\title{
The Formation of Quasicrystal Phase in Al-Cu-Fe System By Mechanical Alloying
}

\author{
Dilermando Nagle Travessa ${ }^{a *}$, Kátia Regina Cardoso ${ }^{a}$, Witor Wolf $^{\mathrm{b}}$, \\ Alberto Moreira Jorge Jr. ${ }^{\mathrm{b}}$, Walter José Botta ${ }^{\mathrm{b}}$ \\ ${ }^{\mathrm{a}}$ Instituto de Ciência e Tecnologia, Universidade Federal de São Paulo - UNIFESP, \\ Rua Talim, 330, CEP 12231-280, São José dos Campos, SP, Brazil \\ ${ }^{\mathrm{b}}$ Departamento de Engenharia de Materiais, Universidade Federal de São Carlos - UFSCar, \\ Rod. Washington Luís, Km 235, São Carlos, SP, Brazil
}

Received: November 30, 2011; Revised: February 15, 2012

\begin{abstract}
In order to obtain quasicrystalline (QC) phase by mechanical alloying (MA) in the $\mathrm{Al}-\mathrm{Cu}-\mathrm{Fe}$ system, mixtures of elementary $\mathrm{Al}, \mathrm{Cu}$ and $\mathrm{Fe}$ in the proportion of 65-20-15 (at. \%) were produced by high energy ball milling (HEBM). A very high energy type mill (spex) and short milling times (up to 5 hours) were employed. The resulting powders were characterized by X-ray diffraction (XRD), differential scanning calorimetry (DSC) and scanning electron microscopy (SEM). QC phase was not directly formed by milling under the conditions employed in this work. However, phase transformations identified by DSC analysis reveals that annealing after HEBM possibly results in the formation of the $\psi \mathrm{QC}$ phase.
\end{abstract}

Keywords: $\mathrm{Al}$-Cu-Fe system, mechanical alloying, quasicrystals

\section{Introduction}

Since the discovery of quasicrystals (QCs) about 30 years ago, many efforts have been made in understanding the structure, properties and the synthesis of these materials. Hundred of systems have been identified as QC formers on both, stable and metastable conditions. Most of these systems are based in aluminum alloyed to transition metals. Although much scientific knowledge has already been raised about the QCs, a technological use of these materials has yet to be achieved. A very promising application seems to be the use as a reinforcing phase in aluminum alloys, due to a set of intrinsic properties.

The icosaedral quasicrystalline $\psi$ phase is stable in a narrow composition range of the $\mathrm{Al}-\mathrm{Cu}-\mathrm{Fe}$ system. This composition is around $\mathrm{Al}_{63} \mathrm{Cu}_{25} \mathrm{Fe}_{12}$ (at. \%), in equilibrium with other crystalline phases like $\beta-\mathrm{AlFe}(\mathrm{Cu}), \lambda-\mathrm{Al}_{13} \mathrm{Fe}_{4}$, $\lambda 1-\mathrm{Al}_{3} \mathrm{Fe}, \theta-\mathrm{Al}_{2} \mathrm{Cu}, \omega-\mathrm{Al}_{7} \mathrm{Cu}_{2} \mathrm{Fe}$ and $\phi-\mathrm{Al}_{10} \mathrm{Cu}_{10} \mathrm{Fe}^{1}$. Among these crystalline phases, $\omega$ shows a great similarity with the icosaedral $\psi$ phase. The coordination of the Fe atoms is very similar in both structures ${ }^{2}$.

From the solidification route, the $\psi$ phase seems to be formed in equilibrium conditions, by a peritectic reaction from a primary crystalline phase ${ }^{1,3,4}$. Non-equilibrium processes like rapid solidification or MA can extend the compositional range of $\psi$, as well as to form metastable disordered approximant phases. HEBM process seems to be suitable for the production of nano-particles due to the continuous process of mixture and fragmentation. However, it seems that quasicrystals are destabilized in presence of high concentration of structural defects ${ }^{5}$ that are common in the HEBM powders.

*e-mail: dilermando.travessa@unifesp.br
The composition of the $\psi$ phase, when formed, depends on the alloy composition, as well as on the composition of the co-existing phases ${ }^{4}$. These aspects make complex the mechanism of QC formation by MA, which is very dependent on the process variables, as well as on the contamination level. Fe excess from the milling media can result in significant changes in the composition of the mixture. The particles initial size, the use of PCA (process control agents), the milling atmosphere, time and energy, which are related to the temperature reached during the process and to the contamination level, strongly affect the alloying mechanisms during the milling. Furthermore, the success in obtaining the QC $\psi$ phase by HEBM in the $\mathrm{Al}-\mathrm{Cu}-\mathrm{Fe}$ system is frequently related to a subsequent annealing at temperatures from 400 to $800^{\circ} \mathrm{C}$ after milling. However, the mechanisms involved in this process are not clearly described. Some authors relate that during the annealing of the milled powder, the $\psi$ phase can be formed from disordered metastable phases that are ordered by the effect of the heating. Other authors state that annealing at high temperatures can lead to liquid formation and the $\psi$ phase could be formed from equilibrium phases through a peritectic reaction.

In the $\mathrm{Al}-\mathrm{Cu}-\mathrm{Fe}$ system, at compositions richer in iron like $\mathrm{Al}_{60} \mathrm{Cu}_{20} \mathrm{Fe}_{15}$, the $\psi$ phase can be formed as a minor component by rapid solidification, and its proportion increases significantly after annealing ${ }^{3}$. HEBM of the same composition can lead to the formation of the $\psi$ phase after annealing at temperatures ranging from 440 to $550{ }^{\circ} \mathrm{C}^{6}$ or at temperatures as high as $750^{\circ} \mathrm{C}^{7}$, or even with no additional annealing, as a minor phase $e^{8,9}$. In compositions with lower 
Fe content (10-12 at. \%), the $\psi$ phase can be obtained by MA without subsequent annealing ${ }^{2,9,10}$, but in this case Fe contamination, mainly from longer milling times, can change the overall composition of the mixture.

Immerse in this context, the present work aims to investigate the formation of the $\psi$ phase in the $\mathrm{Al}-\mathrm{Cu}-\mathrm{Fe}$ system by mechanical alloying, under very high energy conditions (spex type mill) and short milling times (up to 5 hours). In addition, the thermal stability of the phases present in the milled powders is also evaluated.

\section{Experimental Procedures}

$\mathrm{Al}, \mathrm{Cu}$ (powder) and $\mathrm{Fe}$ (1-2 mm pellets), in the proportion of $\mathrm{Al}_{65} \mathrm{Cu}_{20} \mathrm{Fe}_{15}$, atomic \%, were HEBM in a Spex ball mill, for 1, 2, 3 and 5 hours, under argon atmosphere. Ball to powder ratio was 10:1 and 1\% (weight) of stearic acid was employed as a process control agent.

The produced powders were characterized by X-ray diffraction (XRD), using a Rigaku Geiger-Flex equipment, at $40 \mathrm{kV} \times 30 \mathrm{~mA}, \mathrm{Cu} \mathrm{K \alpha}$ radiation $(\lambda=1,54056 \AA)$ and $2 \theta$ from 5 to $90^{\circ}$ at $2 \% \mathrm{~min}$ and a step of 0,032 degree/s, in order to verify the level of mixture during the milling, as well as to identify the phases eventually formed during HEBM. Differential scanning calorimetry (DSC) Netzsch DSC 200 F3 Maia, under constant argon flux and heating rate of $40 \mathrm{~K} / \mathrm{min}$, was also performed in order to evaluate the thermal stability of the mixture and to verify the occurrence of phase transformations induced by heating. Scanning electron microscopy (SEM) FEI Magellan 400 L was employed to verify the powder morphological and size evolution along the process.

\section{Results and Discussion}

Figure 1 shows the XRD analysis of the as milled powders. Peaks of elementary $\mathrm{Al}, \mathrm{Cu}$ and $\mathrm{Fe}$ are predominant in the powders milled for 1 hour, but small peaks identified as the $\theta$ phase are already present. As the milling time increases, $\mathrm{Al}$ and mainly $\mathrm{Cu}$ peaks decrease significantly. The $\theta$ peaks seems to reach its maximum intensity in the powder milled for 2 hours, decreasing thereafter. Fe peaks remain visible even in powders milled for 5 hours. It seems

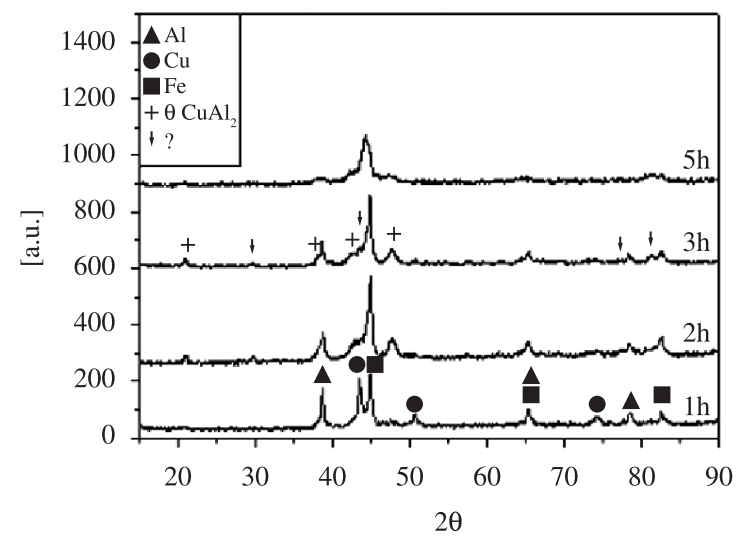

Figure 1. XRD spectra obtained for the powders milled for different times: 1, 2, 3 and 5 hours. that the lower solubility and diffusivity of $\mathrm{Fe}$ than $\mathrm{Cu}$ in $\mathrm{Al}$ is responsible for this effect. Besides, the starting size of the $\mathrm{Fe}$ pellets was greater than the $\mathrm{Al}$ and $\mathrm{Cu}$ powders. Some weak unidentified peaks occur for all milling times. Similar results were obtained in several works using planetary mills and longer milling times ${ }^{2,8,9-12}$, although the presence of $\beta$ or even $\psi$ phases, besides the $\theta$ phase, are also reported in these works. The presence of X-ray diffraction lines from the elementary powders after 2 and 3 hours of milling made difficult the identification of other phases having diffraction lines at $2 \theta$ ranging from 43 to $45^{\circ}$ and that were supposed to form.

An unidentified peak appears at the edge of the mean Fe peak, becoming more evident in the powder milled for 5 hours. This peak at $2 \theta=44^{\circ}$, in association to other unidentified peak at the position around $2 \theta=81^{\circ}$ could be associated to $\lambda, \beta 1-\mathrm{AlFe}_{3}$ or even to a metastable $\gamma-\mathrm{Al}_{4} \mathrm{Cu}_{9}$ phase $^{13}$. However the small amount of peaks that could be related to these phases does not allow a precise identification.

DSC spectra of the milled powders are seen in Figure $2 \mathrm{a}$. A detailed view reveals that an exothermic peak around $150{ }^{\circ} \mathrm{C}$ is observed in the powder milled for 1 hour (Figure 2b). This peak decreases after 2 hours of milling (Figure 2c), disappearing for greater milling times. This peak could be associated to the $\theta$ phase formation, as it reduces for higher milling times, where $\theta$ forms directly from the milling process as observed in XRD (Figure 1). DSC peaks at this temperature were also related to powder stress relief ${ }^{14}$, but it seems to be not the case in the present work, as their intensity reduces and disappear with longer milling times. Salimon et al. observed the formation of $\theta$ and $\beta$ phases after annealing the Al-Cu-Fe mechanically alloyed powders at this temperature range ${ }^{15}$. However, higher temperatures are also reported for $\theta$ formation: $330{ }^{\circ} \mathrm{C}$ (along with the $\omega$ phase $)^{6}, 400^{2,10}$ and $580{ }^{\circ} \mathrm{C}^{7}$.

A small exothermic peak is observed at $350{ }^{\circ} \mathrm{C}$ in the powder milled for 2 hours. This peak is also present in the powders milled for longer times and can be associated with the formation of the $\omega$ phase $^{6,14}$. As the phase $\omega$ is identified as a precursor of the simultaneous formation of the $\psi$ and $\beta$ phases $^{6,13}$, the high energy exothermic peaks observed in all milling times in the range of 432 to $458{ }^{\circ} \mathrm{C}$, could be associated to a massive formation of both phases. Finally, the endothermic peaks at 540 and $585{ }^{\circ} \mathrm{C}$, observed in the powders milled for 1 hour, can be associated with $\theta$ and $\mathrm{Al}$ fusion, respectively. The peaks are very small in the powder milled for 2 hours and disappear in powders milled for 3 and 5 hours. The pseudo binary $\lambda-\theta$ phase diagram ${ }^{7}$ reveals that the $\theta$ melts at $585^{\circ} \mathrm{C}$. Although the melting temperature of $\mathrm{Al}$ is normally around $660{ }^{\circ} \mathrm{C}$, it can be reduced by the presence of small amounts of $\mathrm{Cu}$ as an impurity ${ }^{14}$.

Figure 3 shows SEM micrographs from the as milled powders. As verified in the XRD analysis, the mixture is not complete after 1 hour of milling. Back-scattering electrons contrast reveals a fine unmixed lamellar structure, along with $\mathrm{Cu}$ and mainly $\mathrm{Fe}$ isolated particles (Figure 1). Although unmixed, the intimate lamellar contact of elements in some particles of the powder can promote solid state reactions under heating, as observed in DSC analysis. Increasing 


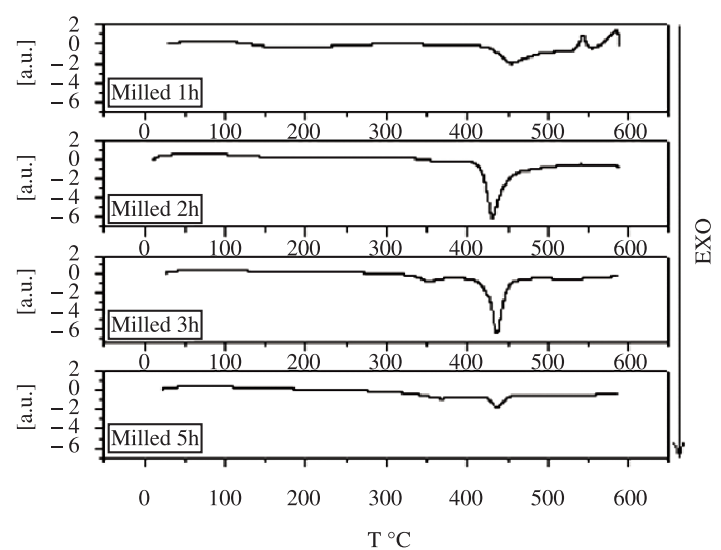

(a)

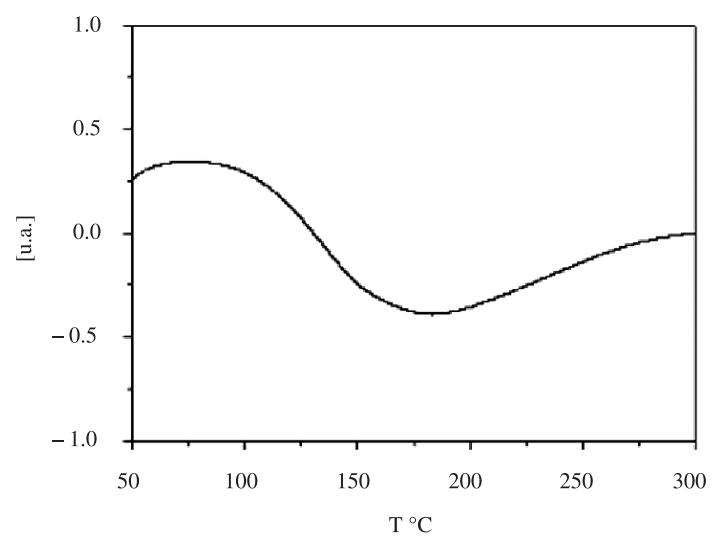

(b)

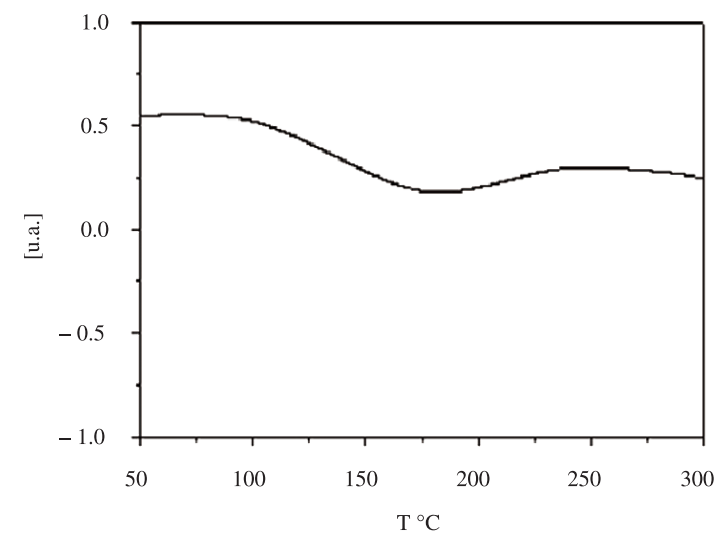

(c)

Figure 2. DSC results obtained for the powders milled for different times: a) overall results; b) detail of exothermic peak of the powder milled for 1 hour, around $150^{\circ} \mathrm{C}$; and c) detail of exothermic peak of the powder milled for 2 hours, around $150{ }^{\circ} \mathrm{C}$.

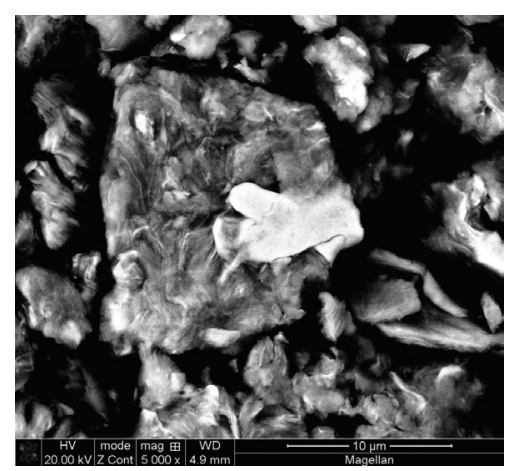

(a)

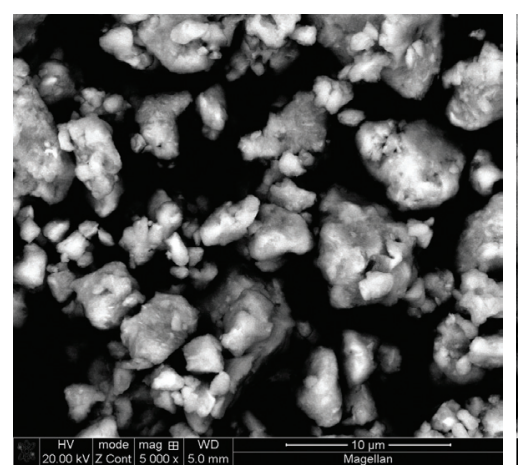

(b)

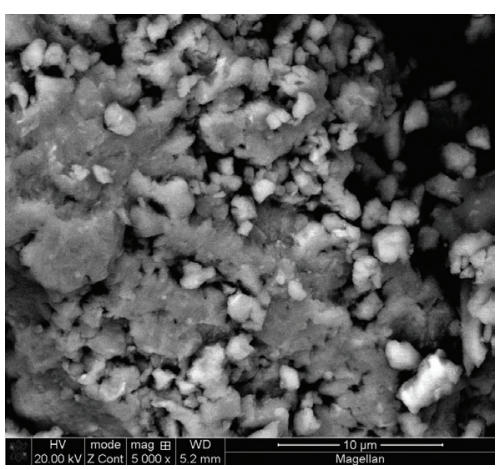

(c)

Figure 3. SEM micrographs of the as milled powders, for different milling times: a) 1 hour; b) 3 hours; and c) 5 hours. Back scattering electrons contrast.

the milling time, the lamellar structure becomes hardly visible, suggesting that alloying starts to occur. In fact, XRD results reveal the $\theta$ phase forms, along with some unidentified phases, mainly in the powders milled for 2 , 3 and 5 hours. Further, the size of the unmixed $\mathrm{Cu}$ and $\mathrm{Fe}$ particles becomes significantly smaller (clear particles in Figure $3 b$ ). After milling for 5 hours, the amount of unmixed particles becomes significantly reduced and the powders tend to agglomerate.

\section{Conclusions}

Based on the experimental conditions employed in this work and its corresponding results, the following conclusions can be drawn: 
The complete mixture of the elementary powders was not complete up to 5 hours milling. However, a fine lamellar structure was obtained, mainly between $\mathrm{Al}$ and $\mathrm{Cu}$, even after only 1 hour milling. This enabled the formation of $\theta$ phase during the milling and several other solid state reactions observed in DSC analysis;

QC phase was not directly formed in the $\mathrm{Al}_{65} \mathrm{Cu}_{20} \mathrm{Fe}_{15}$ alloy by HEBM, using a very high energy mill, even after milling for 5 hours. Instead, $\theta$ and other unidentified phases

\section{References}

1. Huttunen-Saarivirta E. Microstructure, fabrication and properties of quasicrystalline Al-Cu-Fe alloys: a review. Journal of Alloys and Compounds. 2004; 363(1-2):150-174. http://dx.doi.org/10.1016/S0925-8388(03)00445-6

2. Yin S, Xie Z, Bian Q, He B, Pan Z, Sun Z et al. Formation of $\mathrm{AlCuFe}$ icosahedral quasicrystal by mechanical alloying: XAFS and XRD studies. Journal of Alloys and Compounds. 2008; 455(1-2):314-321. http://dx.doi.org/10.1016/j. jallcom.2007.01.058

3. Rosas G and Perez R. On the nature of quasicrystal phase transitions in $\mathrm{AlCuFe}$ alloys. Materials Letters. 1998; 36(1-4):229-234. http://dx.doi.org/10.1016/S0167577X(98)00033-0

4. Suárez MA, Esquivel R, Alcántara J, Dorantes H and Cháves JF. Effect of chemical composition on the microstructure and hardness of Al-Cu-Fe alloy. Materials Characterization. 2011; 62(1):917-923.

5. Grushko B and Velikanova TY. Stable and metastable quasicrystals in Al-based alloy systems with transition metals. Journal of Alloys and Compounds. 2004; 367(1-2):58-63. http://dx.doi. org/10.1016/j.jallcom.2003.08.012

6. Kim KB, Kim SH, Kim WT, Kim D-H and Hong K-T. Structural evolution during heat treatment of mechanically alloyed Al$\mathrm{Cu}-\mathrm{Fe}-(\mathrm{Si})$ alloys. Materials Science and Engineering. 2001; A304-306;822-829.

7. Yong $\mathrm{X}$, Chang IT and Jones IP. Formation of a quasicrystalline phase in mechanically alloyed $\mathrm{Al}_{65} \mathrm{Cu}_{25} \mathrm{Fe}_{15}$. Journal of Alloys and Compounds. 2005; 387(1-2):128-133. http://dx.doi. org/10.1016/j.jallcom.2004.06.082

8. Murty BS, Barua P, Srinivas V, Schurack F and Eckert J. Synthesis of $\left(\mathrm{Al}_{65} \mathrm{Cu}_{20} \mathrm{Fe}_{15}\right)_{100-\mathrm{X}} \mathrm{Si}_{\mathrm{x}}$ quasicrystalline alloys by mechanical alloying. Journal of Non-Crystalline seem to form after 2 hours of milling. The $\lambda, \beta 1$ or the metastable $\gamma$ phases could be related to these peaks;

DSC analysis of the milled powders shows that some exothermic phase transformations take place during heating, the most significant around $440{ }^{\circ} \mathrm{C}$. The literature supports the hypothesis that this reaction can be associated to the formation of the $\beta$ and $\psi$-QC phases, from a previous $\omega$ phase formed at lower temperatures. Further XRD analysis on annealed powders is necessary to support this hypothesis.

Solids. 2004; 334-335;44-47. http://dx.doi.org/10.1016/j. jnoncrysol.2003.11.010

9. Murty BS, Koteswara Rao RV and Mukhopadhyay NK. Stability of quasicrystalline phase in $\mathrm{Al}-\mathrm{Cu}-\mathrm{Fe}, \mathrm{Al}-\mathrm{Cu}-\mathrm{Co}$ and Al-Pd-Mn systems by high energy ball milling. Journal of Non-Crystalline Solids. 2004; 334-335;48-51.

10. Yin $\mathrm{S}$, Bian Q, Qian $\mathrm{L}$ and Zhang A. Formation of $\mathrm{Al}_{70} \mathrm{Cu}_{20} \mathrm{Fe}_{10}$ icosahedral quasicrystal by mechanically alloyed method. Materials Science and Engineering A. 2007; 465(1-2):95-99. http://dx.doi.org/10.1016/j.msea.2007.03.092

11. Srinivas V, Barua P and Murty BS. On icosahedral phase formation in mechanically alloyed $\mathrm{Al}_{70} \mathrm{Cu}_{20} \mathrm{Fe}_{10}$. Materials Science and Engineering. 2000; 294-296;65-67. http://dx.doi. org/10.1016/S0921-5093(00)01200-4

12. Barua P, Murty BS, Mathur BK and Srinivas V. Nanostructured icosahedral phase formation in $\mathrm{Al}_{70} \mathrm{Cu}_{20} \mathrm{Fe}_{10}$ by mechanical alloying: Comprehensive study. Journal of Applied Physics. 2002; 91(8):5353-5359. http://dx.doi.org/10.1063/1.1464206

13. Nicula R, Turquier F, Stir M, Kodash VY, Groza JR and Burkel E. Quasicrystal phase formation in $\mathrm{Al}-\mathrm{Cu}-\mathrm{Fe}$ nanopowders during field-activated sintering (FAST). Journal of Alloys and Compounds. 2007; 434-435;319-323. http://dx.doi. org/10.1016/j.jallcom.2006.08.195

14. Proveti JR, Larica C and Passamani EC. Structural properties and phase transformation in mechanically alloyed $\mathrm{Al} / \mathrm{Cu} /$ Fe system. Journal of Physics D: Applied Physics. 2003; 36(7):798-804. http://dx.doi.org/10.1088/0022-3727/36/7/305

15. Salimon AI, Korsunsky AM, Shelekhov EV, Sviridova TA, Kaloshkin SD, Tchrdyntsev VS et al. Crystallochemical aspects of solid state reactions in mechanically alloyed Al-Cu-Fe quasicristalline. Acta materialia. 2001; 49(10):1821-1833. http://dx.doi.org/10.1016/S1359-6454(01)00077-5 